\title{
A prospective study on the efficacy and safety of ferric carboxymaltose in correcting anaemia in patients with heavy menstrual bleeding
}

\begin{abstract}
Background: More than $50 \%$ of women in the developing countries are affected with iron deficiency anaemia. Ongoing blood loss in women with heavy menstrual bleeding can pose a difficulty to combat anaemia in these patients. Ferric carboxymaltose (FCM) is a novel molecule which can be safely administered at large doses in a very short time.
\end{abstract}

Objective: This prospective study was designed to study the efficacy and safety of ferric carboxymaltose in treating anaemia in women with heavy menstrual bleeding.

Material and method: This hospital based prospective study included 65 anaemic $(\mathrm{Hb}<10 \mathrm{gm} \%)$ women with heavy menstrual bleeding. Diagnosis of iron deficiency anemia was established by peripheral blood smear and serum ferritin level. About $1000 \mathrm{mg}$ FCM was given by infusion in 15 minutes and improvement in haemoglobin and serum ferritin was assessed 14 days after the infusion. Any side effects were recorded during the study. Results were statistically analysed by paired t test.

Result: The mean haemoglobin before and after administration of FCM infusion were $7.71 \pm 0.66 \mathrm{gm} \%$ and $10.33 \pm 1.21 \mathrm{gm} \%$ respectively. The mean difference in haemoglobin was $2.62 \mathrm{gm} \%$. ( $<<0.0001)$. The mean ferritin level before and after FCM infusion were $26.77 \pm 22.0 \mathrm{ng} / \mathrm{ml}$ and $254.75 \pm 70.00 \mathrm{ng} / \mathrm{ml}$ respectively. Mean difference in ferritin was $227.97 \mathrm{ng} / \mathrm{ml}(\mathrm{p}<0.0001)$. No major adverse reactions were seen.

Conclusion: This study demonstrated the safety and efficacy of FCM in treating anaemia in patients with heavy menstrual bleeding and should be considered in such women to avoid the possible need of blood transfusion.

Keywords: ferric carboxy maltose, iron deficiency anaemia, efficacy, heavy menstrual bleeding
Volume 9 Issue 5 - 2018

\section{Sharma Nalini, J LalnunnenThiek, Rituparna Das, Ahanthem Santa Singh}

Department of Obstetrics and Gynaecology, North Eastern Indira Gandhi Regional Institute of Health and Medical Sciences, India

\author{
Correspondence: Nalini Sharma, Assistant Professor, \\ Department of Obstetrics and Gynecology, B I D, North \\ Eastern Indira Gandhi Regional Institute of Health and Medical \\ Sciences Shillong, Meghalaya, 793018, India, Tel 9774066673, \\ Email Nalinisharmi I00@rediffmail.com
}

Received: June 03, 2018 | Published: October 09, 2018

\section{Introduction}

According to WHO reports, anaemia is one of the most common and wide spread disorders in the world affecting about 2 billion people and resulting in an estimated global prevalence of about $25 \%$. In developing countries, anaemia affects more than half of school children and women and this incidence is at least $30-40 \%$ in developed world. ${ }^{1}$ Among the several causes of anaemia, iron deficiency is undoubtedly the most common cause and oral iron is the first mode of therapy with iron deficiency anaemia (IDA) but its ability to replenish iron store is limited by patient compliance problems due to gastrointestinal side effects. Treatment with parenteral iron could present some advantage over oral iron by leading to a rapid and higher increase of hemoglobin levels and body iron stores. ${ }^{2}$

Ferric carboxymaltose (FCM) is a new intravenous iron formulation. It is a polynuclearIron (III)-hydroxide carbohydrate complex designed to mimic physiologic ferritin. It is a water-soluble compound with molecular weight of 150000 Dalton containing approximately 1000 iron atoms which correspond to an iron content of $24-32 \%$. FCM complex has neutral $\mathrm{pH}(5-7)^{3}$ and has physiologic osmolarity. FCM does not contain dextran or modified dextran and does not react with dextran antibodies thus having a very low immunogenic potential and therefore does not predispose to anaphylactic reaction. ${ }^{4} \mathrm{FCM}$ has a ferric hydroxide core stabilized by a carbohydrate shell. There is controlled delivery of iron to the cells of reticuloendothelial system ${ }^{5}$ and subsequent delivery to iron binding protein with minimal risk of large amount of ionic iron being released into the circulation. These properties permit the administration of iron in large doses $(15 \mathrm{mg} / \mathrm{kg}$, maximum of $1000 \mathrm{mg} /$ infusion) during a single and rapid session (15 minute infusion) without the requirement of test dose.., 7

The management of iron deficiency anaemia includes the treatment of underlying cause and replacement of body iron stores. However, in patients with heavy menstrual bleeding, treatment of anaemia can be difficult due to ongoing blood loss. These patients often require preoperative or postoperative blood transfusion. Intravenous iron preparation can be given to replace iron and replenish iron stores rapidly. To date, few clinical studies showed the efficacy of FCM in correcting anaemia in patients with heavy menstrual bleeding. ${ }^{8,9}$ There is no study which investigates the efficacy and safety of FCM in North eastern population of India. This study was designed to see the efficacy and safety of FCM in correcting iron deficiency anemia of Indian women with heavy menstrual bleeding. 


\section{Materials and methods}

The study was a prospective study done over a period of two years at the obstetrics and gynaecology department of a tertiary health centre in the northeastern India. Our primary objective was to evaluate the efficacy of FCM in correcting iron deficiency anaemia in women with heavy menstrual bleeding. Our secondary objective was to specify the safety profile of FCM treatment. Approval was taken from the institutional ethical committee. All patients with gynaecological disorder and haemoglobin less than $10 \mathrm{~g} / \mathrm{dl}$, which provided informed consent and agreed upon complete follow up, were included in this study. The exclusion criteria were anaemias unrelated with iron deficiency, receival of blood transfusion, and known allergy to parenteral iron therapy. Complete haemogram, serum ferritin and peripheral blood smear for cell morphology were done before administering ferric carboxymaltose by infusion and the same parameters except peripheral blood smear were repeated after two weeks. A total of 65 patients were given $1000 \mathrm{mg}$ ferric carboxymaltose (Orofer FCM, Emcure Pharma) in $250 \mathrm{ml}$ of normal saline over 15 minutes. Adverse effects like nausea, vomiting, hypotension, headache, fever, pain, tingling sensation or itching at the injection site during the infusion of ferric carboxymaltose were noted.

\section{Statistical analysis}

Collected data were expressed as mean \pm standard deviation using descriptive statistics. Paired samples t test was performed to compare the mean values determined before and after transfusion. All $p$ values less than 0.05 within $95 \%$ confidence interval and at $5 \%$ level of significance were considered to be statistically significant

\section{Results}

This study included a total of 65 patients with various gynaecological disorders and haemoglobin less than $10 \mathrm{~g} / \mathrm{dl}$. The baseline demographic profiles of the patients are shown in Table 1. The mean age and parity of the study population were $38.96 \pm 9.77$ years and $2.35 \pm 1.75$ respectively. The underlying gynaecological disorders associated with anaemia are enlisted in Table 2.The mean haemoglobin before and after administration of FCM were $7.71 \pm$ $0.66 \mathrm{~g} / \mathrm{dl}$ and $10.33 \pm 1.21 \mathrm{~g} / \mathrm{dl}$ respectively $(p<0.0001)$. The mean difference in haemoglobin was $2.62 \mathrm{~g} / \mathrm{dl}$. The mean ferritin level before and after FCM infusion were $26.77 \pm 22.08 \mathrm{ng} / \mathrm{ml}$ and $254.75 \pm 70.00 \mathrm{ng} /$ $\mathrm{ml}$ respectively (Table 3 ). The mean increase in serum ferritin level after FCM infusion was statistically significant $(227.97 \mathrm{ng} / \mathrm{ml}, p$ $<0.0001)$. No major adverse reactions were observed except pain at the site of injection in three cases, nausea in two cases and headache in one patient (Table 4).

Table I Demographic \& baseline data of women

\begin{tabular}{ll}
\hline Parameters & Mean \\
\hline Age (years) & $38.96 \pm 9.77$ \\
Parity & $2.35 \pm \mathrm{I} .75$ \\
Hemoglobin $(\mathrm{g} / \mathrm{dl})$ & $7.7 \mathrm{I} \pm 0.66$ \\
Ferritin $(\mathrm{ng} / \mathrm{ml})$ & $26.77 \pm 22.08$ \\
\hline
\end{tabular}

Table 2 Underlying gynecological disorders

\begin{tabular}{ll}
\hline Diagnosis & Number \& percentage \\
\hline Uterine fibroid & $15(23 \%)$ \\
Post-operative status & $13(20 \%)$ \\
Dysfunctional uterine bleeding & $12(18.5 \%)$ \\
Adenomyosis & $6(9.2 \%)$ \\
Postmenopausal bleeding & $4(6.2 \%)$ \\
Cervix cancer & $4(6.2 \%)$ \\
Endometrial polyp & $4(6.2 \%)$ \\
Juvenile bleeding & $3(4.6 \%)$ \\
Others & $4(6.1 \%)$ \\
\hline
\end{tabular}

Table 3 Comparison of mean haemoglobin and ferritin values

\begin{tabular}{llll}
\hline $\begin{array}{l}\text { Parameter } \\
\text { (mean) }\end{array}$ & $\begin{array}{l}\text { Before ferric } \\
\text { carboxymaltose } \\
\text { infusion }\end{array}$ & $\begin{array}{l}\text { After ferric } \\
\text { carboxymaltose } \\
\text { infusion }\end{array}$ & $\mathbf{P}$ \\
\hline Hemoglobin $(\mathrm{g} / \mathrm{dl})$ & $7.7 \mathrm{I} \pm 0.66$ & $10.33 \pm \mathrm{I} .2 \mathrm{I}$ & $<0.000 \mathrm{I}$ \\
Ferritin $(\mathrm{ng} / \mathrm{ml})$ & $26.77 \pm 22.08$ & $254.75 \pm 70.00$ & $<0.000 \mathrm{I}$ \\
\hline
\end{tabular}

Table 4 Adverse reactions with ferric carboxymaltose infusion

\begin{tabular}{ll}
\hline Adverse reaction & Number of patients \\
\hline Headache & 1 \\
Nausea, vomiting, diarrhoea & 2 \\
Rigor & 0 \\
Fever & 0 \\
Pain/burning at injection site & 3 \\
Hypotension/hypertension & 0 \\
Tingling sensation at injection site & 0 \\
Itching at injection site & 0 \\
Severe anaphylactic reaction & 0
\end{tabular}

\section{Discussion}

Present study confirmed the efficacy and safety of FCM infusion in treating IDA in women with heavy menstrual bleeding. Fourteen days after the infusion of FCM, the mean increase in haemoglobin and ferritin values were $2.62 \mathrm{gm} / \mathrm{dl}$ and $227.98 \mathrm{ng} / \mathrm{ml}$ respectively and this difference was statistically significant $(\mathrm{p}<0.0001$ for both). Our findings were consistent with two other previously published studies which were performed in women with heavy menstrual bleeding related IDA..$^{8,9}$

A study by Van Wyck et al showed a mean increase of $2 \mathrm{~g} / \mathrm{dl}$ or more in haemoglobin within 42 days and anaemia was corrected in about $73 \%$ of the women (Haemoglobin $>12 \mathrm{~g} / \mathrm{dl}$ ). The same study showed a mean increase up to $3 \mathrm{~g} / \mathrm{dl}$ in haemoglobin after 14 days of FCM administration.

The efficacy and safety of FCM treatment in the correction of IDA was demonstrated in patients with various medical disorders like 
inflammatory bowel disorders, chronic renal disorders not requiring dialysis, chronic renal disorders requiring dialysis and cardiac failure. $^{10-12}$

Two retrospective studies mentioned the efficacy and safety profile of FCM in pregnant women with IDA..$^{14,15}$ In these studies FCM was administered in second and third trimesters with an increase in mean hemoglobin values from $8.4 \mathrm{~g} / \mathrm{dl}$ to $11 \mathrm{~g} / \mathrm{dl}$. No adverse events related with treatment and no adverse obstetric outcomes were reported.

In another study FCM infusion was given in pregnancy. Patients were divided into three groups as per severity. For all three severity group, haemoglobin levels increased post infusion at 3 and 6 weeks, to be significantly higher than base line level $(\mathrm{p}<0.010)$. However, the postpartum hb levels were only significantly higher than base line in the mild IDA $(\mathrm{P}<0.01)$ Minor side effects occurred in $20 \%$ patients. ${ }^{16}$

In one more study in pregnant women, ferric carboxy maltose compared with oral iron Ferrous sulfate (FS). Hb levels improved at comparable rates across both treatment, However significantly more woman achieved anemia correction with FCMvs FS (Hb $>=11 \mathrm{~g} / \mathrm{dl}$, $84 \% \mathrm{vs} 70 \% \mathrm{P}=0.031$ ) and within shorter time frame (median $3.4 \mathrm{vs}$ 4.3 weeks). Treatment related adverse events were experienced in FCMwas $11 \%$ as compare to FS $(15 \%)^{17}$

In one more study by patricia FCM was compared with IS in antenatal women. Mean rise of $\mathrm{Hb}$ value was $15.4 \mathrm{~g} / \mathrm{l}$ for FCM and $11.7 \mathrm{~g} / \mathrm{dl}$ for IS. The incidence of drug induced adverse events was low and mild in both the groups. ${ }^{18}$

There are several studies which documented the efficacy and safety of FCM treatment in postpartum anaemia. ${ }^{19-22} \mathrm{~A}$ study by Von Wyck et al. demonstrated an earlier rise of haemoglobin $(\geq 2 \mathrm{~g} /$ dl) with FCM when compared to oral iron (7 days compared with 14 days) and an increase $\geq 3 \mathrm{~g} / \mathrm{dl}$ in hemoglobin was noted after 7 days in $86.3 \%$ of postpartum women. While comparing the efficacy and safety of FCM with iron sucrose, Sharma et al reported an increase of $3.14 \mathrm{~g} / \mathrm{dl}$ in mean haemoglobin and an increase of $125.91 \mathrm{ng} / \mathrm{ml}$ in mean ferritin values after 14 days after they treated postpartum anaemia with FCM infusion. The FCM treatment is also found to be efficacious in improving haemoglobin values of anaemic patients who are to undergo surgery. ${ }^{23}$

In one study with 457 patients, after 6 weeks of FCM infusion. increase in $\mathrm{Hb}$ level by $>$.or $=2 \mathrm{~g} / \mathrm{dl}$ was attained by $41 \%$ of all the patient, $40 \%$ in the disease of digestive system group, $55 \%$ in the disease of genitourinary system groups, $26 \%$ in the neoplasm groups and $29 \%$ in the disease of circulatory system. Hb increase of $>=3 \mathrm{~g} /$ $\mathrm{dl}$ after 6 weeks after FCM dose was attained by $20 \%$ of all patients ,24\% of the patients in the IDAgroup, $22 \%$ in the diseases of digestive system, $26 \%$ in the disease of genitourinarysystem, 115 in the neoplasm group and $16 \%$ in the diseases of circulatory system Groups. ${ }^{24}$

In one systematic review, FCM when compared to other iron formulation, performed better in the achievement of a rapid and consistent $\mathrm{Hb}$ response. A higher increase in serum ferritin was also observed in patients receiving FCM comparing to other therapy. ${ }^{25}$

Another study compared FCM with iron dextran (ID) and Iron sucrose (IS) in iron deficiency anaemia. There was increase in $\mathrm{Hb}$ concentration significantly greater in both IS and FCM group compared to ID ( $\mathrm{p}=0.04$ and, 0.01 respectively). However there was no statistically significant difference between the groups treated in IS and FCM. There was significant increase in both mean serum ferritinin concentration and mean MCV after treatment in all groups. ${ }^{26}$

In the present study, adverse effects associated with FCM infusion were mild and temporary. All the patients had uneventful recovery after receiving FCM infusion. Various adverse effects like nausea, injection site pain, headache, hypertension, constipation, fatigue, dizziness and vomiting were minimal and momentary. Adverse effects relted with FCM treatment resemble those observed in other studies. ${ }^{9,19-22}$

Surgery or blood transfusion or both may be required several times in patients with menorrhagia. Red cell transfusion is not only costly and short in supply but also has its well described risks and side effects. In moderate to severe anaemia related with heavy menstrual bleeding, the administration of FCM infusion can avoid the need of blood transfusion as it results in a rapid rise in hemoglobin levels. This study displays the safety and efficacy of FCM infusion in treating the anaemia of patients with heavy menstrual bleeding and, thu the need for blood transfusion could be avoided.

The power of the present study was limited by relatively small number of women and shorter follow up period of patients.

\section{Conclusion}

This study demonstrated the safety and efficacy of FCM infusion in treating anaemia in patients with heavy menstrual bleeding. The FCM treatment should be considered in such women to avoid the possible need of blood transfusion.

\section{Acknowledgments}

None.

\section{Conflict of interests}

Authors declare that there is no conflict of interest.

\section{References}

1. McLean E, Cogswell M, Egli I, et al. Worldwide prevalence of anaemia, WHO Vitamin and Mineral Nutrition Information System, 1993-2005. Public Health Nutr 2009;12(4):444-444.

2. Friedrisch JR, Cancado RD. Intravenous ferric carboxymaltose for the treatment of iron deficiency. Rev Bras Hematol Hemoter. 2015;37(6):400-405.

3. Funk F, Ryle P, Canclini C,et al. The new generation of intravenous iron: chemistry, pharmacology, and toxicology of ferric carboxymaltose. Arzneimittelforschung. 2010;60:345-353.

4. Bailie GR, Mason NA, Valaoras TG. Safety and tolerability of intravenous ferric carboxymaltose in patients with iron deficiency anemia. Hemodial Int. 2010;14(1):47-54.

5. Lyseng-Williamson KA, Keating GM. Ferric carboxymaltose: a review of its use in iron-deficiency anaemia. Drugs. 2009;69:739-756.

6. Geisser P, Banke-Bochita J. Pharmacokinetics, safety and tolerability of intravenous ferric carboxymaltose: a dose-escalation study in volunteers with mild iron-deficiency anaemia. Arzneimittel-Forschung. 2010;60(6):362-372.

7. Moore A, Gaskell H, Rose P et al. Meta-analysis of efficacy and safety of intravenous ferric carboxymaltose (Ferinject) from clinical trial reports and published trial data. BMC Blood Disorders. 2011;11:4. 
8. Van Wyck DB, Mangione A, Morrison $\mathrm{J}$ et al. Large-dose intravenous ferric carboxymaltose injection for iron deficiency anemia in heavy uterine bleeding: a randomized, controlled trial. Transfusion 2009;49(12): 2719-2728.

9. Herfs R, Fleitmann L, Kocsis I. Treatment of Iron deficiency with or without anaemia with intravenous ferric carboxymaltose in gynaecological practices - a non-interventional study. Geburtshilfe Frauenheilkd. 2014;74(1):81-88.

10. Evstatiev R, Marteau P, Iqbal T, et al. FERGI Study Group. FERGIcor, a randomized controlled trial on ferric carboxymaltose for iron deficiency anemia in inflammatory bowel disease. Gastroenterol 2011;141(3):846-853.

11. Klaire E, Nancy T, Andrea A, Atif K, Shahed A. Efficacy and safety profile of single dose IV FCM in the management of renal anaemia-a single centre experience. Nephrol Dial Transplant. 2013;28(1):363-364.

12. Covic A, Mircescu G. The safety and efficacy of intravenous ferric carboxymaltose in anaemic patients undergoing haemodialysis: a multicentre, open-label, clinical study. Nephrol Dial Transplant. 2010;25(8):2722-2730

13. Anker SD, Comin Colet J, Filippatos G, et al. FAIR-HF Trial Investigators: Ferric carboxymaltose in patients with heart failure and iron deficiency. $N$ Engl J Med. 2009;361(25):2436-2448.

14. Rodriguez RA, Montero MG, Lorente Aporta JP, et al. Clinical Study Retrospective Case Reports of Anemic Pregnant Women Receiving Intravenous Ferric Carboxymaltose: Experience from a Tertiary Hospital in Spain. Obstet Gynecol Int. 2016;2016:5060252.

15. Pels A, Ganzevoort WJ. Safety and Efficacy of Ferric Carboxymaltose in Anemic Pregnant Women: A Retrospective Case Control Study. Obstet Gynecol Int. 2015;2015:728952.

16. Froessler B, Collingwoo J, Hodyl NA, et al. Intravenous ferric carboxymaltose for anaemia in pregnancy. BMC Pregnancy and Childbirth. 2014:14:115.

17. Christoph $\mathrm{P}$, Schuller $\mathrm{C}$, Studer $\mathrm{H}$, Irion $\mathrm{O}$, et al. Intravenous iron treatment in pregnancy: comparison of high-dose ferric carboxymaltose vs. iron sucrose. J Perinat Med. 2012;40(5):469-474.
18. Breymann C, Milman N, Mezzacasa A, et al. Ferric carboxymaltose vs. oral iron in the treatment of pregnant women with iron deficiency anemia: an international, open-label, randomized controlled trial (FER-ASAP). $J$ Perinat Med. 2017;45(4):443-453.

19. Sharma N, Thiek LJ, Natung T, et al. Comparative Study of Efficacy and Safety of Ferric Carboxymaltose versus Iron Sucrose in Post-partum Anaemia. J Obstet Gynecol India. 2017;67(4):253-257.

20. Seid MH, Derman RJ, Baker JB,et al. Ferric carboxymaltose injection in the treatment of postpartum iron deficiency anemia: A randomized controlled clinical trial. Am J Obstet Gynecol. 2008;199: 4351-4357.

21. VanWyck DB, Martens MG, Seid $M H$,et al. Intravenous ferric carboxymaltose compared with oral iron in the treatment of postpartum anemia:Arandomized controlled trial. Obstet Gynecol. 2007;110:267-278.

22. Rathod S, Samal SK, Mahapatra PC. Ferric carboxymaltose: a revolution in the treatment of postpartum anemia in Indian women. Int J Appl Basic Med Res. 2015;5(1):25-30.

23. Bisbe E, Garcia-Erce JA, Diez-Lodo AI, et al. A multicentre comparative study on the efficacy of intravenous ferric carboxymaltose and iron sucrose for correcting preoperative anaemia in patients undergoing major elective surgery. Br J Anaesth. 2011;107(3):477-478.

24. Nunes AR, Costa AP, Rocha SL, et al. efficacy and Tolerability of Intravenous Ferric Carboxymaltose in Patients with Iron Deficiency at a Hospital Outpatient Clinic: A Retrospective Cohort Study of Real-World Clinical Practice. Anemia. 2017:1-7.

25. Rognoni C, Venturini S, Meregaglia M, et al. Efficacy and Safety of Ferric Carboxymaltose and Other Formulations in Iron-Deficient Patients: A Systematic Review and Network Meta-analysis of Randomised Controlled Trials. Clin Drug Investig. 2016;36(3):177-194.

26. Dillon R, Momoh I, Francis Y, et al. Comparative efficacy of three Forms of Parenteral Iron. J blood Transfus. 2012:473514. 